\title{
BONE BLOCK AUGMENTATION - A LONG TERM FOLLOW-UP
}

\author{
Stefan Peev, Elitsa Sabeva \\ Department of Periodontology and Dental Implantology, Faculty of Dental Medicine, \\ Medical University of Varna
}

\begin{abstract}
INTRODUCTION: Autogenous bone block grafting is used for both vertical and horizontal augmentation of the upper and lower jaw. The bone block could be provided using extraoral or intraoral donor location.

Aim: The aim of this study was to observe the survival rate, the marginal bone level and the bleeding on probing (BOP) for a period of 4 to 6 years of implants, inserted in autogenous bone block graft.

MATERIALS AND METHODS: We considered advanced horizontal bone loss, where guided bone regeneration with simultaneous implant placement could not be performed and/or vertical bone loss, where vertical augmentation of the alveolar bone of more than 3 to $6 \mathrm{~mm}$ is required, as indications for the bone block grafting procedure. As an intraoral donor site was used the mental area.

RESULTS AND DISCUSSION: The mean observation period was 4.81 years. The mean marginal bone loss was $0.442 \mathrm{~mm}$, as bone resorption was established in $48 \%$ of all cases, BOP was observed in $17.7 \%$ of the cases. No correlation was found between BOP and bone loss. The survival rate of the implants placed into bone augmented using autogenous bone block graft was $98.7 \%$.

CONCLUSION: For an implant placement we considered a period of 4 months after the procedure enough to provide high survival rate of the implants. The implants placed in bone augmented using autogenous bone block grafting according to our methodology demonstrated high survival rate and unstable marginal bone level.
\end{abstract}

Keywords: bone block graft, implant placement

Address for correspondence:

Stefan Peev

Faculty of Dental Medicine

Medical University of Varna

84 Tsar Osvoboditel Blvd

9000 Varna

e-mail:Stefan.Peev@mu-varna.bg

Received: October 27, 2018

Accepted: December 15, 2018

\section{INTRODUCTION}

Autogenous block grafting is used for both vertical and horizontal augmentation of the upper and lower jaw (1). The origin of the bone block may be an extraoral donor location: crista iliaca (2-22), the calvaria $(4,8,14,15,20)$. For the same purpose intraoral donor sites could also be used: the mentum $(8,9,15,23)$ and the lower jaw angle (24). The authors describe a success rate of 90 to $100 \%$ of bone block grafting pro- 
cedures and survival rate of the implants, over a period of 6 to 24 months, of 60 to $100 \%$ (87\% mean value). Over the same period, survival and success rate of the implants is higher with the delayed approach, at which augmentation precedes implant placement, compared to the simultaneous approach, when the reconstruction is followed by implant placement at the same stage. Reported complications are: $3.3 \%$ dehiscence of the graft and 1.4\% loss of the whole graft $(8,11)$.

In addition to autogenous bone in the literature are described also studies with an onlay block graft of allogeneic demineralized bone (24), alloplastic materials in combination with autogenous bone (22), as well as the use of alloplastic blocks with or without growth factors (25). Chiapasco et al. (26), in a systematic literature review, reported that there is insufficient data to draw a conclusion about the use of nonautogenous block grafts. At the same time, the analysis of the studies on the autogenous bone block graft leads to the following conclusion: bone loss is highest in the first year after the reconstruction and in the first year after the start of the functional loading of the implants placed in the augmented areas. The loss of graft volume due to resorption is related to the donor site - the highest volume loss is described in iliac grafts - 12 to $60 \%$, and the lowest - in bone blocks of calvaria. It seems that cortical bone thickness of the bone block is essential for the loss of bone volume over time. The use of a membrane definitely decreases the loss of graft volume. According to Block and Degen (27) using lyophilized allogenic bone without membrane application and consolidation time of 4 months, onlay graft resorption observed, causing volume loss of up to $50 \%$ of the initial bone volume. Previous studies offer that functional loading of the implants placed in an autogenous bone block graft occurs 6 to 12 months after implantation, because of the need of more time for implant integration $(27,28)$. At the same time there is an obvious volume loss during this period. Sjostrom et al. (29) using resonance frequency analysis established that 24 weeks after implantation in augmented bone implants show similar implant stability quotient (ISQ) values compared to implants placed in non-augmented bone. The authors took notice of this fact in support of their thesis about earlier functional loading.
In an experimental study, De Santis et al. (30) compared the results of block grafting at four-walled defects recovered using autogenous bone blocks and blocks of deproteinized bovine bone mineral. Both materials were covered with a collagen barrier membrane. Six months after surgery, autogenous bone blocks were properly integrated and remodeled, while deproteinized bovine bone mineral blocks were infiltrated by a fibrous connective tissue and only a small part of them that contacted directly with the recipient bone bed seemed integrated with it, which led to the apparent immobility of the bone blocks. The implants placed in both types of blocks showed similar results - from full osseointegration (the autogenous bone block) to partial integration (block of deproteinized bovine bone mineral) - close to the walls of the recipient bone bed.

\section{AIM}

The aim of this study was to observe the survival rate, the marginal bone level and the bleeding on probing (BOP) for a period of 4 to 6 years of implants, inserted in autogenous bone block graft.

\section{MATERIALS AND METHODS}

The measurements of the existing alveolar bone of the patients considered for bone block grafting was done using cone-beam computed tomography. We considered as indicated for bone block grafting procedure, patients with advanced horizontal bone insufficiency, which does not allow the performance of guided bone regeneration with simultaneous implant placement, and vertical bone insufficiency, which requires augmentation of 3 to $6 \mathrm{~mm}$ in vertical direction. We used autogenous bone grafts, derived from the mental area. The planning and the measurements of the bone block were done using cone-beam computed tomography. There should be a distance of at least $5 \mathrm{~mm}$ between the upper edge of the bone block and the projection of the apexes of the lower anterior teeth on the anterior surface of the lower jaw. The mesial end of the autogenous block extends to the symphysis of the lower jaw, the caudal - to the lower frontal edge of the lower jaw and the distal boundary reached the mandibular canal, according to its anatomical variations. The thickness of the autogenous bone block may represent half of the thickness of the lower jaw in the relevant area (Fig. 1). 


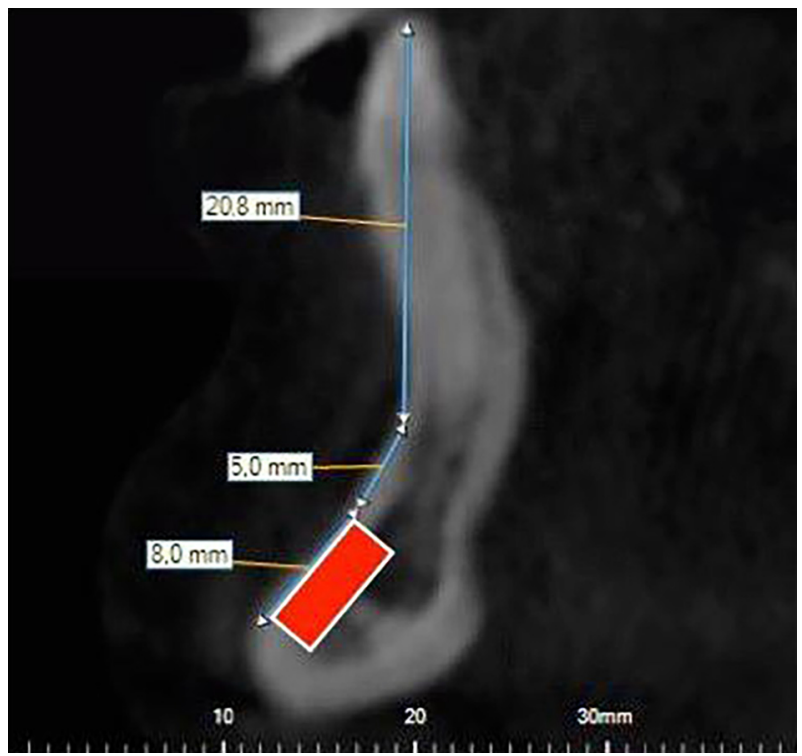

Fig. 1. Paraxial reconstruction in the area of planned autogenous bone block

The preparation of the recipient site was done before taking the autogenous bone block. The preparation of the recipient side included elevation of mucoperiosteal flap in the area subject to augmentation. The preparation of the bone block was performed using an incision in the mucogingival junction area in the relevant region. After that, a flap was elevated and the elevation of the periosteum and the muscle insertions in the area was performed very cautiously. The osteotomy was done to the planned depth, but not less than the thickness of the compact bone in the relevant section. The bone block was elevated using a curved chisel (Fig. 2). The donor site was filled with bone grafting material (Fig. 3) and was covered

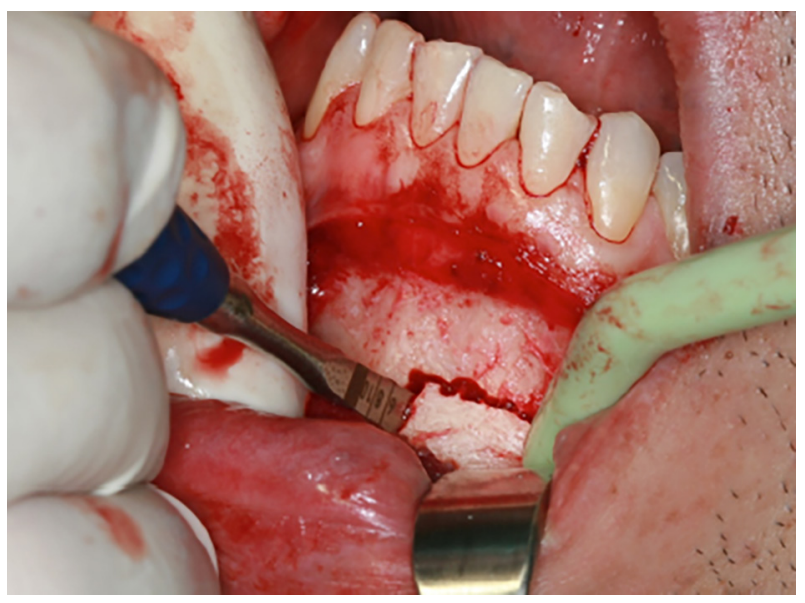

Fig. 2. Elevation of the bone block using curved chisel

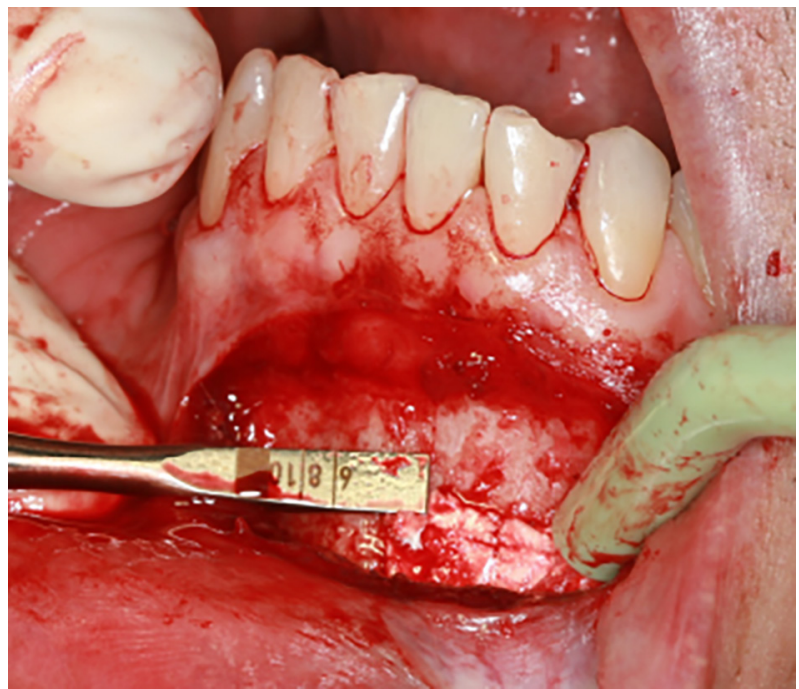

Fig. 3. Filling the donor site with bone grafting material

using a barrier membrane. The mucoperiosteal flap was repositioned and sutured.

The fastening of the bone block at the recipient site started after fixation with a suitable tool (bone fixation forceps - Aesculap AG) (Fig. 4). The fixation was performed using a $1.5 \mathrm{~mm}$ diameter microscrews (bone block fixation - Institut Straumann AG, Basel, Switzerland), the screw channel in the bone block was done using a $1.5 \mathrm{~mm}$ drill (Fig. 5), and in the walls of the recipient site it was done using a 1.25 $\mathrm{mm}$ drill. Once the bone block was fixed, it was covered with bone grafting material (Fig. 6) and colla-

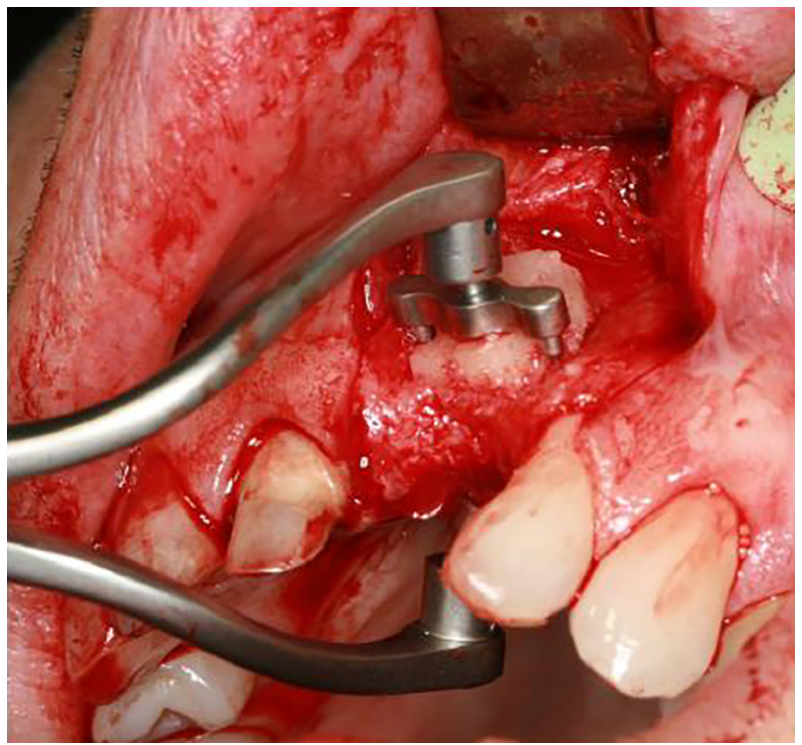

Fig. 4. Fixation of the bone block at the recipient site using bone fixation forceps 


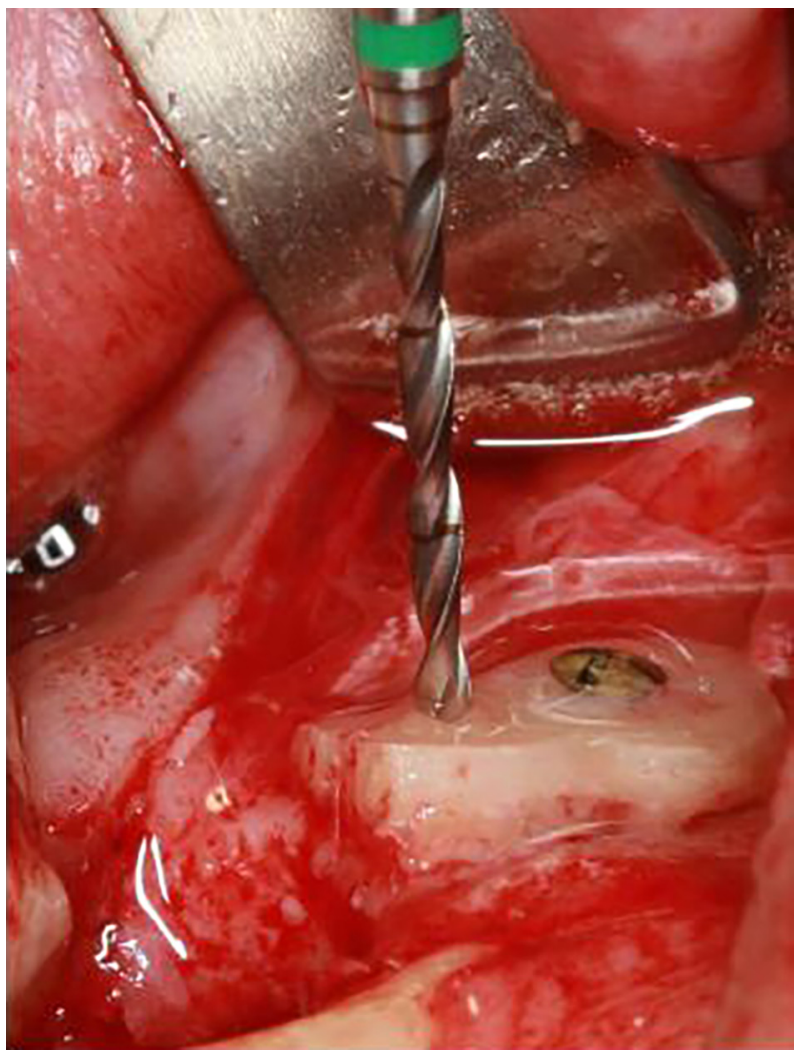

Fig. 5. The screw channel in the bone block was done using a $1.5 \mathrm{~mm}$ drill

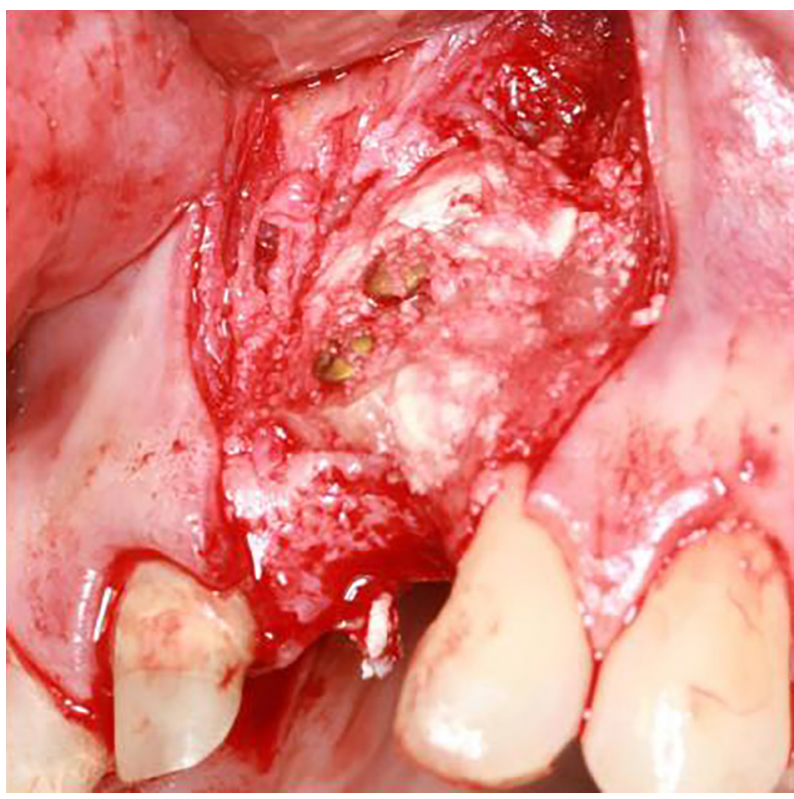

Fig. 6. The bone block is covered with bone grafting material

gen barrier membrane (Fig. 7). After that the flap was mobilized, repositioned and sutured using monofila-

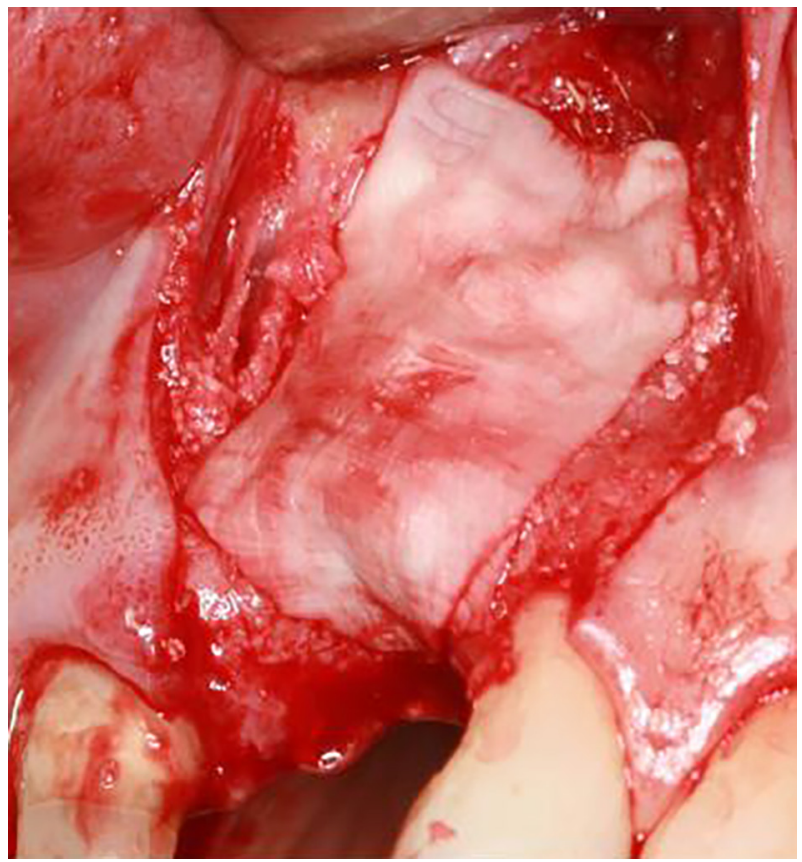

Fig. 7. The bone block and the bone grafting material are covered with collagen barrier membrane

ment suture material (Dafilon, B. Braun-Melsungen, Germany).

The following indicators were observed:

1. Presence of intraoperative and postoperative complications of donor and recipient site.

2. Survival rate for the observed period.

3. The presence of bone resorption visible on radiographic examination.

4. Bleeding on probing (established using UNC-15).

The data was analyzed using IBM SPSS Statistics 19.

\section{RESULTS}

We followed the cases of implant placement into bone augmented using autogenous bone block graft procedure over a period of time of 4 to 6 years (mean 4.81 years with a standard deviation of 0.533 ). The mean age of the patients was 34.25 years. Depending on the area, where the procedure was performed, the distribution of the cases was as indicated on Fig.8. The method was used in the upper anterior area mainly in cases of horizontal bone deficiency, while in the lower distal area - mostly with a vertical bone insufficiency (Fig. 9). The implants were loaded after a mean period of 3.11 months with a standard 


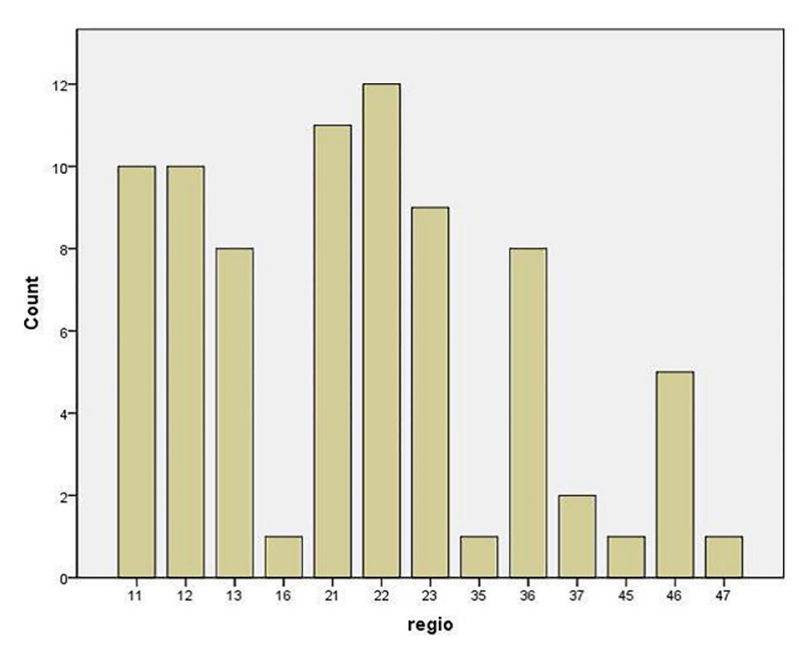

Fig. 8. Distribution of the cases depending on the area

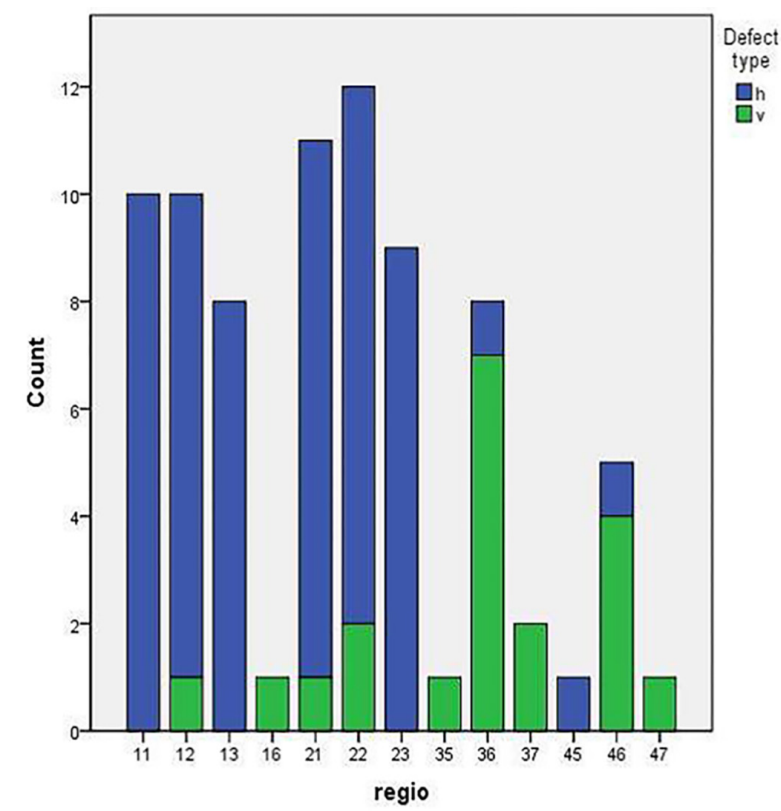

Fig. 9. Distribution of the cases depending on the area and type of bone deficiency: h-horizontal; v-vertical

deviation of 0.320 . Bleeding on probing was observed in $17.7 \%$ of all cases. Correlation between bone resorption and bleeding on probing was not established. The survival rate of the implants was $98.7 \%$.

The complication rate was $21.5 \%$. In $17.7 \%$ of the cases dehiscence of the membrane and/or the graft was observed. In none of the cases special treatment due to complications was required. In $3.8 \%$ of the complications vitality loss of the teeth near the donor site was established. It required endodontic treatment of the affected teeth. In none of the cases of vitality loss no more than one tooth at same clinical case was affected.

\section{DISCUSSION}

The survival rate of the implants was $98.7 \%$. This is high survival rate exceeding the results reported by the majority of published studies $(2,3,4,5,6$, $7,9,10,13,14,16,24)$ and is similar to the results published by Bell et al. (17), Verhoeven et al. (11), Chiapasco et al. (15), and Levin et al. (31). The implants were placed 4 to 6 months after the augmentation procedure, which did not affect the results. Marginal bone loss was $0.442 \mathrm{~mm}$, which is significantly higher value than that established at guided bone regeneration with simultaneous implant placement. That gave us a reason to conclude that the performance of the method alone, especially in the aesthetic area, is inappropriate because of the impossibility of maintaining volume stability, as well as soft tissue aesthetics for a long period of time. It could also be suggested, in cases of advanced bone loss, requiring the performance of bone block grafting procedure with delayed implant placement, to perform at second surgical stage guided bone regeneration with simultaneous implant placement in an already augmented via bone block graft in order to ensure the volume stability of the restored tissues.

\section{CONCLUSION}

According to the investigated method, the implant placement in bone, augmented via block grafting procedure, demonstrated high survival rate of the implants $-98.7 \%$ and unstable marginal bone level with mean value of marginal bone loss of 0.442 $\mathrm{mm}$ for the observed period. A four-month period is sufficient for implant placement into bone augmented via block graft in order to ensure a high survival rate of the implants.

\section{REFERENCES}

1. Chiapasco M, Casentini P, Zaniboni M. Bone augmentation procedures in implant dentistry. Int J Oral Maxillofac Implants. 2009;24 Suppl:237-59.

2. Adell R, Lekholm U, Gröndahl K, Brånemark PI, Lindström J, Jacobsson M. Reconstruction of severely resorbed edentulous maxillae using osseointegrated fixtures in immediate autogenous bone grafts. Int J Oral Maxillofac Implants. 1990;5(3):233-46. 
3. Jensen J, Sindet-Pedersen S. Autogenous mandibular bone grafts and osseointegrated implants for reconstruction of the severely atrophied maxilla: A preliminary report. J Oral Maxillofac Surg. 1991;49(12):1277-87.

4. Donovan MG, Dickerson NC,Hanson LJ, Gustafson RB. Maxillary and mandibular reconstruction using calvarial bone grafts and Brånemark implants: A preliminary report. J Oral Maxillofac Surg. 1994;52(6):588-94.

5. McGrath CJR, Schepers SHW, Blijdorp PA, Hoppenreijs TJM, Erbe M. Simultaneous placement of endosteal implants and mandibular onlay grafting for treatment of the atrophic mandible. A preliminary report. Int J Oral Maxillofac Surg. 1996;25(3):184-8.

6. Åstrand P, Nord PG, Brånemark PI. Titanium implants and onlay bone graft to the atrophic edentulous maxilla. Int J Oral Maxillofac Surg. 1996;25(1):25-9.

7. Vermeeren JIJF, Wismeijer D, van Waas MAJ. Onestep reconstruction of the severely resorbed mandible with onlay bone grafts and endosteal implants. A 5-year follow-up. Int J Oral Maxillofac Surg. 1996;25(2):112-5.

8. Triplett RG, Schow SR. Autologous bone grafts and endosseous implants: Complementary techniques. Int J Oral Maxillofac Surg. 1996;54(4):486-94.

9. Schliephake H, Neukam FW, Wichmann M. Survival analysis of endosseous implants in bone grafts used for the treatment of severe alveolar ridge atrophy. J Oral Maxillofac Surg. 1997;55(11):1227-33.

10. van Steenberghe D, Naert I, Bossuyt M, De Mars G, Calberson L, Ghyselen J, et al. The rehabilitation of the severely resorbed maxilla by simultaneous placement of autogenous bone grafts and implants: A 10-year evaluation. Clin Oral Investig. 1997;1(3):102-8.

11. Verhoeven JW, Cune MS, Terlou M, Zoon MA, de Putter C. The combined use of endosteal implants and iliac crest onlay grafts in the severely atrophic mandible: A longitudinal study. Int J Oral Maxillofac Surg. 1997;26(5):351-7.

12. Lundgren $S$, Nyström E, Nilson H, Gunne J, Lindhagen $\mathrm{O}$. Bone grafting to the maxillary sinuses, nasal floor and anterior maxilla in the atrophic edentulous maxilla. A two-stage technique. Int J Oral Maxillofac Surg. 1997;26(6):428-34.
13. Widmark G, Andersson B, Andrup B, Carlsson GE, Ivanoff CJ, Lindvall AM. Rehabilitation of patients with severely resorbed maxillae by means of implants with or without bone grafts. A 1-year follow-up study. Int J Oral Maxillofac Implants. 1998;13(4): 474-82.

14. Keller EE, Tolman DE, Eckert S. Surgical-prosthodontic reconstruction of advanced maxillary bone compromise with autogenous onlay block bone grafts and osseointegrated endosseous implants: A 12 -year study of 32 consecutive patients. Int J Oral Maxillofac Implants. 1999;14(2):197-209.

15. Chiapasco M, Abati S, Romeo E, Vogel G. Clinical outcome of autogenous bone blocks or guided bone regeneration with e-PTFE membranes for the reconstruction of narrow edentulous ridges. Clin Oral Implants Res. 1999;10(4):278-88.

16. Lekholm U, Wannfors $K$, Isaksson S, Adielsson B. Oral implants in combination with bone grafts. A 3-year retrospective multicenter study using the Brånemark implant system. Int J Oral Maxillofac Surg. 1999;28(3):181-7.

17. Bell RB, Blakey GH,White RP, Hillebrand DG, Molina A. Staged reconstruction of the severely atrophic mandible with autogenous bone graft and endosteal implants. J Oral Maxillofac Surg. 2002;60(10):1135-41.

18. Becktor JP, Eckert SE, Isaksson S, Keller EE. The influence of mandibular dentition on implant failures in bone-grafted edentulous maxillae. Int J Oral Maxillofac Implants. 2002;17(1):69-77.

19. Raghoebar GM, Schoen P, Meijer HJA, Stellingsma K, Vissink A. Early loading of endosseous implants in the augmented maxilla: A 1-year prospective study. Clin Oral Implants Res. 2003;14(6): 697-702.

20. Iizuka T, Smolka W, Hallermann W, Merickse-Stern R. Extensive augmentation of the alveolar ridge using autogenous calvarial split bone grafts for dental rehabilitation. Clin Oral Implants Res. 2004;15(5):607-15. doi: 10.1111/j.1600-0501.2004.01043.x.

21. Nyström E, Ahlqvist J, Gunne J, Kahnberg KE. 10-year follow-up of onlay bone grafts and implants in severely resorbed maxillae. Int J Oral Maxillofac Surg. 2004;33(3):258-62. doi: 10.1006/ ijom.2003.0512.

22. van der Meij EH, Blankestijn J, Berns RM, Bun RJ, Jovanovic A, Onland JM, et al. The combined use of two endosteal implants and iliac crest onlay 
grafts in the severely atrophic mandible by a modified surgical approach. Int J Oral Maxillofac Surg. 2005;34(2):152-7. doi: 10.1016/j.ijom.2004.05.007.

23. Jemt T, Lekholm U. Measurements of buccal tissue volumes at single-implant restorations after local bone grafting in maxillas: A 3-year clinical prospective study case series. Clin Implant Dent Relat Res. 2003;5(2):63-70.

24. Bahat O, Fontanessi RV. Efficacy of implant placement after bone grafting for three-dimensional reconstruction of the posterior jaw. Int J Periodontics Restorative Dent. 2001;21(3): 221-31.

25. Huse RO, Quinten Ruhe P, Wolke JGC, Jansen JA. The use of porous calcium phosphate scaffolds with transforming growth factor beta 1 as an onlay bone graft substitute. Clinical Oral Implants Research. 2004;15(6): 741-9. doi: 10.1111/j.1600-0501.2004.01068.x.

26. Chiapasco M, Zaniboni M, Boisco M. Augmentation procedures for the rehabilitation of deficient edentulous ridges with oral implants. Clin Oral Implants Res. 2006;17(Suppl. 2):136-59. doi: 10.1111/j.1600-0501.2006.01357.x.
27. Block MS, Degen M. Horizontal ridge augmentation using human mineralized particulate bone: preliminary results. J Oral Maxillofac Surg. 2004;62(9 Suppl 2):67-72.

28. Isaksson $S$, Alberius,P. Maxillary alveolar ridge augmentation with onlay bone grafts and immediate endosseous implants. J Craniomaxillofac Surg. 1992;20(1):2-7.

29. Sjostrom M, Lundgren S, Nilson H, Sennerby L. Monitoring of implant stability in grafted bone using resonance frequency analysis. A clinical study from implant placement to 6 months of loading. Int J Oral Maxillofac Surg. 2005;34(1):45-51. doi: 10.1016/j.ijom.2004.03.007.

30. De Santis E, Lang NP, Scala A, Vigano P, Salata LA, Botticelli D. Healing outcomes at implants installed in grafted sites: an experimental study in dogs. Clin Oral Implants Res. 2012;23(3):340-50. doi: 10.1111/j.1600-0501.2011.02326.x.

31. Levin L, Nitzan D, Schwartz-Arad D. Success of dental implants placed in intraoral block bone grafts. J Periodontol. 2007;78(1):18-21. doi: 10.1902/ jop.2007.060238. 